\title{
Building an e-Learning Application Using Multi-agents and Fuzzy Rules
}

\author{
Magdi Amer ${ }^{1}$ and Hossam Aldesoky ${ }^{2,3}$ \\ ${ }^{1}$ Cognizant Digital Engineering \\ ${ }^{2}$ The higher Institute of Social Work, Cairo, Egypt \\ ${ }^{3}$ Deanship of Development and Quality, Umm Qura University, Mecca, Saudi Arabia \\ magdi.amer@cognizant.com \\ hossamaldesoky@yahoo.com
}

\begin{abstract}
One of the biggest challenges in education is teaching mathematics, especially to children. It has been proven that difficulties students face when learning basic mathematics are often the result of previously acquired misconceptions. These misconceptions prevent the student from understanding new concepts and will eventually create a psychological barrier that prevents the student from learning more advanced mathematics. The conventional classroom environment does not provide the teacher with the most efficient means to detect and correct such misconceptions. The goal of our research is to develop an e-learning system for basic mathematics that is capable of providing each student with personalized content to overcome these misconceptions. The system uses a multi-agent architecture to monitor the activity of the student while simultaneously observing and modeling the student's knowledge and misconceptions. Lessons and exam questions are chosen dynamically by the multi-agent system to cover the prerequisites of new lessons depending on the profile of the user.
\end{abstract}

Keywords: Multi-agents, e-learning and Fuzzy rules

\section{Introduction}

Teaching mathematics to primary students is one of the biggest challenges in the modern education system. The high inter-dependency of the mathematical concepts makes any misunderstanding in the basic concepts hard to overcome in later years. The modern education system and the typical classroom environment provide material in a way that is convenient for the majority of students. However, the classroom environment does not provide the teacher with the ability to take into consideration the specific misunderstandings of a student and the differences in cognitive learning ability between students. The current education system does not provide students facing difficulties with customized content suitable to the students' abilities and weaknesses. The result is a high rate of students facing difficulties with mathematics in an education system that is not capable of addressing and improving. It has been proven that children who are facing difficulties in mathematics do not lack a 'math gene' (Devlin, 2001), meaning that there is no special mental disability that they have which prevents them from excelling in mathematics. Instead, it was found that difficulties in mathematics are often due to pre-acquired misconceptions that can prevent them from understanding advanced mathematical concepts.

Teachers in a typical classroom environment do not possess the means and the time to detect the misconceptions of each student and to correct them. As a result, the teacher will overlook the mathematical shortcomings of a large number of students. This results in a significant number of students who are held back from learning advanced mathematical concepts, as the psychological barrier and rapid pace of newer concepts being introduced leaves them behind their peers.

This problem manifests itself even more for children with Dyscalculia (Kucian et al., 2014, Kucian et al., 2011), which is a mathematics learning disability. Recent studies have demonstrated that the rate of dyscalculia ranges between $3 \%$ and $6 \%$ among the general population (Kucian et al., 2011), although it is often undiagnosed (Berch, 2017, Karoll, 2008). It has been proven that the brain of a student with dyscalculia is capable of forming connections that compensate to a great degree the effect of dyscalculia if the student is provided with the proper educational tools (Kucian et al., 2011).

The goal of this paper is to describe an e-learning system for teaching basic mathematics. The system monitors the progress of each student to build the student's profile, which includes the student's knowledge and misconceptions. Based on the student's profile, the system will dynamically select content suitable to the needs and abilities of the student. This is done through the use of multi-agents system (Wooldridge, 2002, 
Franklin and Graesser, 1997) and the use of fuzzy logic to build the user profile and to arbitrate between conflicting agents.

In the next section, a summary of the state of the art will be provided. An overview of the system will be provided next, followed by the details about the multi-agent architecture that was used to build the system. The conclusion will be presented in the final section.

\section{Current Research in Learning and e-learning}

Delvin (2001) refutes the idea that mathematics is associated with special abilities or genes that is only available to an elite subset of the population. On the contrary, the author demonstrates that mathematical ability is similar to language ability but at a higher abstract level.

Russell et al. stated that most mathematical tests do not provide enough information on the student's level in each sub-domain and do not identify why the student has performed poorly within these sub-domains (Russell et al., 2009). These limitations can be overcome when using computer-based assessments. This motivated the authors to develop an online assessment system designed to measure students' comprehension of specific algebraic concepts, which are variables, equality, and graphing, and to identify misconceptions related to them. The system also provides teachers with lesson plans and accompanying materials for each misconception that has been diagnosed in their classroom. The authors used this online assessment test on four groups of students, each group with varying access level to the ability report, the misconception report and to the related materials for each misconception. Statistical results showed that groups having more access to results and material performed higher than the others.

Goguadze et al. (2011) used a Bayesian model to represent students' misconceptions related to decimal number concepts. In order to achieve that, each test question was associated with a list of false answers and each false answer was linked to a misconception with a certain probability. In the learning phase, test results are used to build the learning profile of the average student, including both knowledge and misconceptions. The actual student results are applied to the standard model to produce a personalized model for each student. McLaren et al. (2012) extended the work to build a computer-based e-learning system for decimal concepts using erroneous examples. The authors recognize that the idea of learning using erroneous examples is controversial, due to the behavioral theory that claims that presenting errors to students will make them more inclined to make those errors. Nevertheless, the authors conducted an experiment in teaching $6^{\text {th }}$ grade students decimal concepts using a computer-based course. The students were divided into two groups, one using erroneous examples while the others used the standard problem-solving approach. The teaching was conducted in a computer room over a week. A post-test exam was conducted at the end of the week, and then another delayed post-test exam was conducted a week later, during which no material related to decimal number was taught. The experiment showed no significant difference in the performance between the two groups on the immediate post-test. On the other hand, in the delayed post-test, there was a significant difference in favor of the group that learned through erroneous examples. The authors interpreted these results as proof that erroneous examples provide a deeper understanding over time and help long-term retention.

Shute et al. (2012) proposed four process adaptive cycles to connect the students with appropriate educational material. Intelligent tutoring systems assess the learning capability of the learner in the interactive environment and develop the model of knowledge, skills and expertise. Hypermedia systems can be made adaptable to the learner's model. Adaptive intelligent tutoring systems (Phobun and Vicheanpanya, 2010) combined intelligent tutoring systems with adaptive hypermedia to store the knowledge and use appropriate concepts for the learner. In the intelligent tutoring system, adaptive testing of the students is also very important in assessing the knowledge and deficiencies of the student. Diagnosis model based on computerized adaptive testing along with domain model of competency, curriculum domain model and student model is essential for performance improvement (Badaracco and Martinez, 2011). Badaracco and Martinez (2013) emphasized that importance of item selection in computerized adaptive testing and proposed fuzzy linguistic information to model the expert knowledge to enhance the accuracy of diagnosis of competency of the student. Intelligent tutoring systems may produce good learning abilities for the students but most of the research is focused on technologically advanced countries. The tutoring scenario changes for less developed countries which do not have the luxury of advanced technology. A good review on intelligent tutoring systems 
for the developing world is presented in Nye, (2015). As the internet access in the household of developing countries increases every day and children in those countries have less access to adequate educational institutions, e-learning is also becoming more and more important and can play the pivotal role in supporting educational needs.

It is observed in the studies that computer technology provided a positive effect on learning mathematics in children (Li and Ma, 2010, Moeller et al., 2015). Computer technology can also be used successfully to improve the basic numerical competencies in children with mathematics learning disabilities (Geary et al., 2012, Bartelet et al., 2014). Serious computer-based games can also enhance the cognitive learning of difficult mathematical concepts and can provide different levels of learning difficulty (Echeverria et al., 2012). A good systematic literature review about the positive impact of serious games on learning can be found in Boyle et al. (2016). The use of erroneous examples was proposed to improve the learning of mathematical concepts for a web based tutoring system (Adams et al., 2014). The idea is based on motivating students to process the material more deeply when they are articulating on the incorrect examples done by others.

Computer assisted collaborative learning (Solimeno et al., 2008), can help students to have low anxiety and high problem-solving efficacy by providing them with different educational opportunities. Computer supported collaborative learning is an interesting research direction in the futuristic e-learning classrooms where debates can help students learn complex concepts. Many approaches including instructor led methods, scripted methods or autonomous creative environment for the students can help build collaborate e-learning framework (Fischer et al., 2013, Goodyear P. and Jones C., 2014). In addition, virtual communities like wikis, forums and virtual worlds can provide successful learning experiences (Zhang et al., 2012, Zhang et al., 2014).

Sullivan, et al. proposed implementation of a particular lesson structure based on posing a challenging task to the students to activate their cognitive thinking (Sullivan et al., 2016). This top-down approach can also be incorporated in the e-learning framework.

Al Duhayyim and Newbury (2018) have built an adaptive e-learning system using fuzzy logic. The teacher deconstructs the learning material into concepts. Each concept is further simplified into sub-concepts that are associated with the parent concept using a fuzzy variable concept weight (CW). The CW reflects the importance of the sub-concept in understanding the concept of the parent concept. The teacher also creates a question bank. Each question is associated with a sub-concept and the teacher enters a Concept Error Value (CEV) to reflect the amount of impact this question should have on the student knowledge assessment of the sub-concept. The student knowledge level is evaluated after each test using a set of fuzzy rules taking into account the CW and the CEV. Future studies will be conducted to evaluate the results of using this application in a classroom.

Eryilmaz and Adabashi (2020) have created an Intelligent Tutoring System for teaching Excel in higher education using Bayesian Networks and Fuzzy Logic. The knowledge model of the course is divided into topics. A question bank is created, in which every question is associated with a topic. Based on the pre-test scores and post test scores, the performance of the student in a specific topic is evaluated using fuzzy rules. The prerequisite dependency between the topics is modeled using a tree of topics. Depending on the Bayesian Networks model result for each student, the system determines the topics with satisfied pre-requisites. This model uses the performance level of the student in each topic, in addition to parameters such as the time spent on questions, sequences of reading pages and reading times to enhance the student's assessment. The system provides the student with a navigation system using drop-down menu that informs the student about which topics are ready to be learned and which are not based on the result of the Bayesian Networks model. Students using this system had a higher mean value on academic performance than the students who studied using the traditional e-learning system (Eryılmaz and Adabashi, 2020). However, this system does not detect misconceptions thus is not suitable to be applied for complex topics such as teaching Math. Furthermore, the question bank does not take into account the difficulty of a question; hence it is not reflected in the assessment of the student level.

Lai and colleagues have studied both the constructive learning methodology, where the learning is performed though an instructor that presents the material to the students, and the collaborative learning methodology, where learning is carried out by group learning as the result of learners working together (Lai et al., 2006). They modeled both learning methodologies as an agent negotiation problem where the learners and the 
instructor negotiate using fuzzy agents to agree on the difficulty of the course content and the level of comprehension that this material provided. A high level of difficulty and a low level of comprehension would allow the learners to choose an alternative course content provided by the instructor. Although this research is interesting, the newly proposed course content is chosen by the learners, not the system, thus there is no guarantee that this alternative content will actually achieve better results. Lai and Lan proposed a conceptual framework for adaptive learning where the negotiation mechanism is used to realign learning sequences dynamically according to the knowledge and responses of the learners (Lai and Lan, 2012). The conceptual framework was implemented in Lai et al. (2012). In this implementation, the system chooses a sequence for teaching a specific learning objective. After each unit, the student is required to answer some questions. The student is also required to enter the knowledge level that he/she believes that they have achieved. If this level is far from the assessment of the system, a negotiation phase occurs where the system may increase its assessment, or the student may decrease his/her assessment. If no agreement is reached, the system will reevaluate the student through another set of questions. If the level of knowledge of the student is satisfactory, the system will proceed with the next element in the sequence. Otherwise, the system will repeat the same learning objective again.

\section{System Overview}

The goal of this system is to monitor the activities of the students and to model the knowledge and misconceptions of each student. When the student requests to start the next lesson, the system examines the prerequisites of the next lesson in the course the student is taking. If the student suffers from misconceptions or missing information in these prerequisites, the system uses a multi-agent approach to determine whether the system will present the student with the lesson in question or present him or her with a lesson chosen to cover these missing information and misconceptions.

At the end of each lesson, an exam will be presented. The distribution of the questions will also be done using a multi-agent approach to test both the concepts of the lesson the student has just taken as well as the areas in which the student has potential misconceptions and missing information.

The diagram shown in Figure 1 provides an overview of the system.

The first step in building the system is to use the help of subject matter expects to decompose the mathematical concepts into a set of Knowledge Elements (KEs). Each KE may be further decomposed into sub knowledge. The sub-knowledge element will be given a weight that reflects the importance of this subknowledge towards understanding the concepts of the parent's knowledge. For example, in Figure 2, the subtraction is decomposed into single digit subtraction, double digits subtractions and multiple digits subtraction, with respective weights of $30 \%, 30 \%$ and $40 \%$. The sum of all weights from one level of KE to its sub-KE should be equal to $100 \%$. This decomposition is repeated if needed, which produces a tree of Kes.

The subject matter experts also indicate the prerequisites of each KE, if any. The importance of this prerequisite towards the understanding of the dependent KE is expressed using a fuzzy variable dependency. The dependency fuzzy variable has 3 labels: low, medium and high dependency. The application uses the JFuzzyLogic (Cingolani and Alcala-Fdez, 2012) library to implement the fuzzy rule system. Figure 3 shows the definition of the dependency fuzzy variable and Figure 4 shows the membership function of the variable.

After the KEs tree has been built, the system allows the different content providers to enter the content of the courses they teach. The content providers may represent a governmental entity, usually the ministry of education, or any other private institute that has developed a teaching material of a course. The system allows having multiple versions of the same course and these different versions may be entered by different content providers or by the same content provider using different teaching styles for each version. 


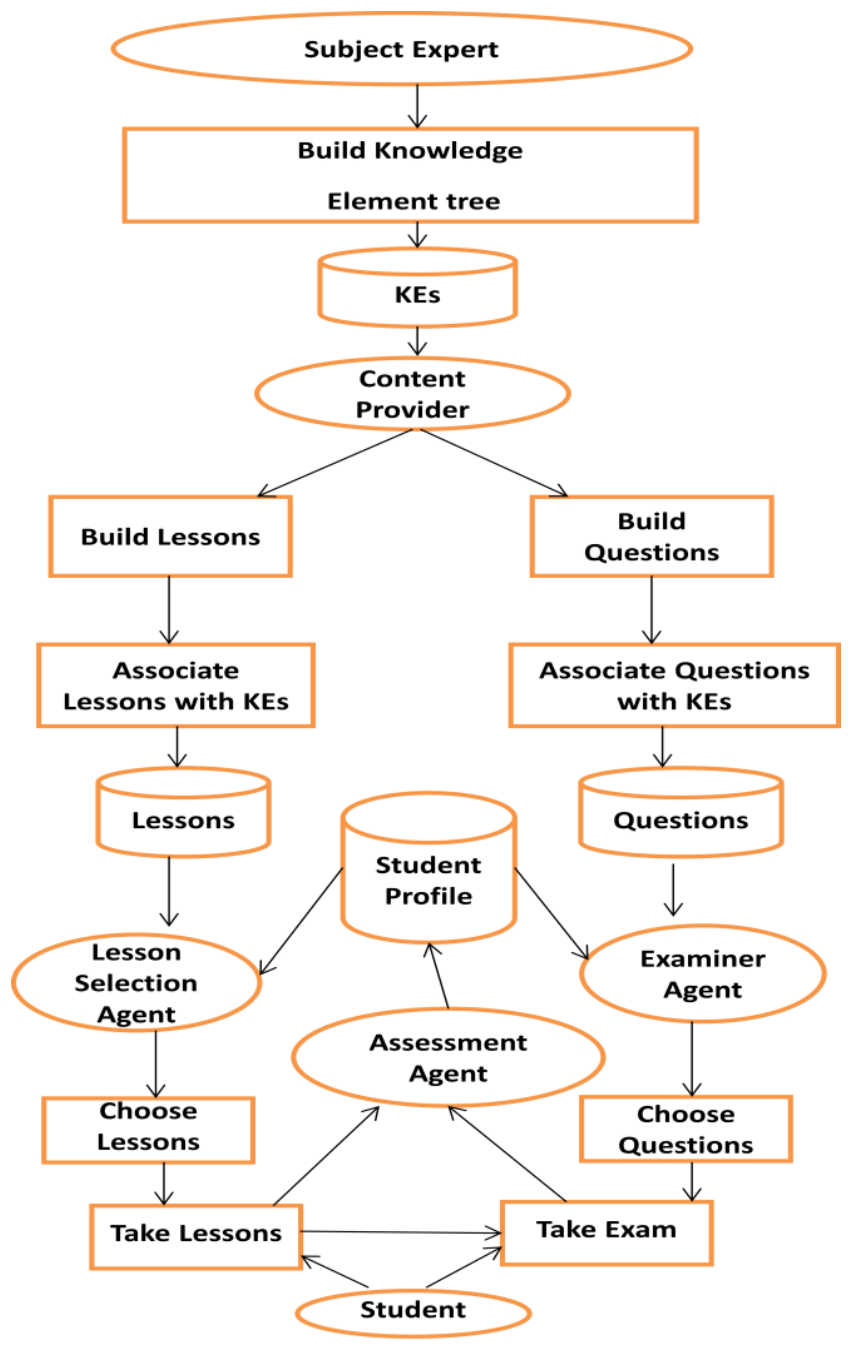

Figure 1: System Overview

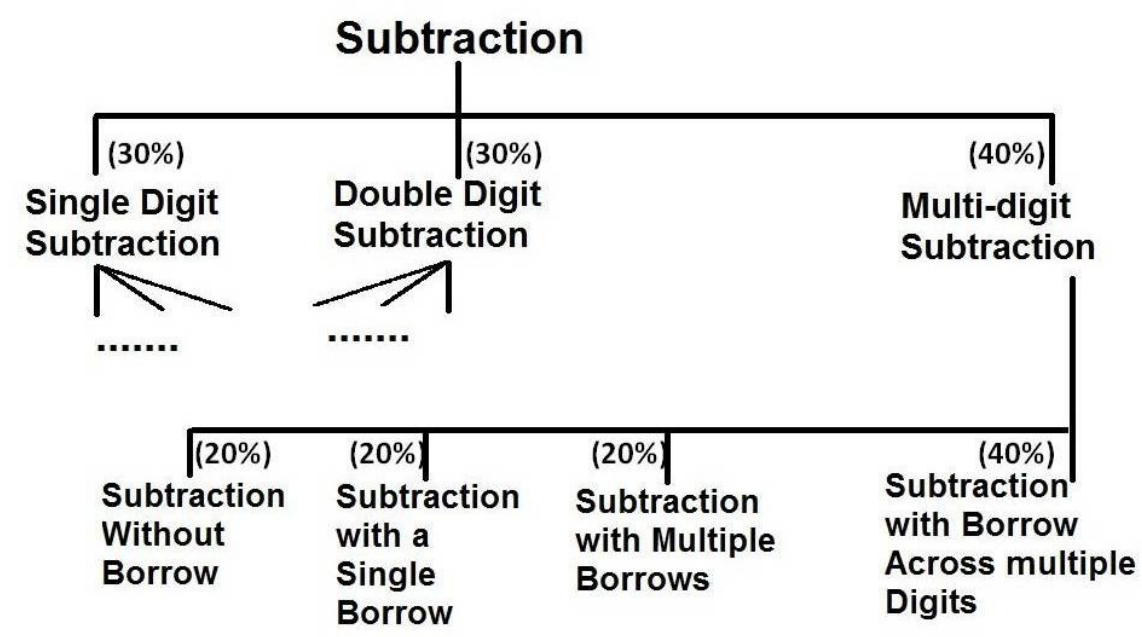

Figure 2: Decomposition of a topic into a tree of Knowledge Elements 


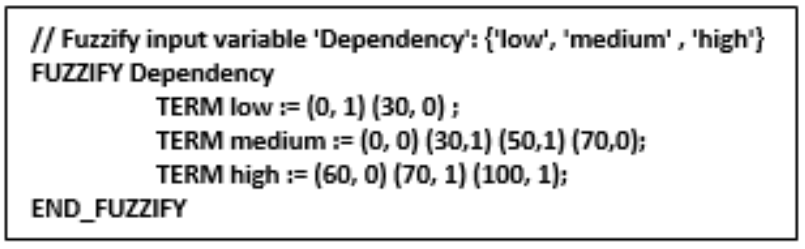

Figure 3: The definition of the fuzzy variable Dependency

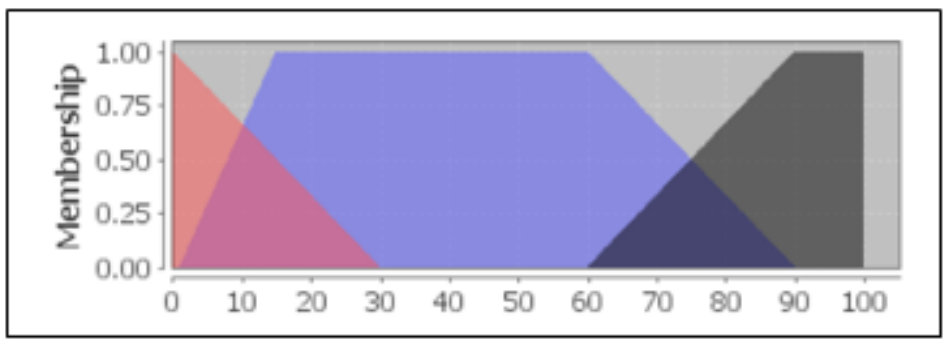

Figure 4: The membership functions of the fuzzy variable Dependency

The content provider enters the course teaching material as a set of ordered lessons. Each lesson is connected with the set of KEs it covers. The link between a lesson and a KE is associated with the fuzzy variable coverage, representing how well the lesson covers the KE. The content provider builds their own units and lessons, reflecting his/her teaching preference and best practices.

After each lesson, the system creates an exam to cover the course the student has just taken and to test for misconceptions and missing knowledge from the student's profile. Content providers provide questions, but the system may decide to include questions provided by other content providers, although a higher priority will always be given to the questions submitted by the course provider. Each question in the system is associated with a set of KEs; this association has a fuzzy variable importance that represents the importance of the understanding of this KE for the student to be able to solve the question. The difficulty of the question is described through the use of the fuzzy-variable difficulty.

The student registers with the system to choose the course he/she will take. Before starting the course, the system will create an assessment exam generated dynamically from a set of questions that cover the prerequisites of this course. To select questions, the system starts with simple, direct questions related to root KEs. If the student answers these questions correctly, the system will then present the student with more difficult questions related to these KEs and some basic questions covering new KEs that are dependent on the KEs that have been tested. If the student was not able to answer some questions successfully, the other dependent KEs are not tested to prevent creating a negative experience for the student. This test will be used to create the models for the knowledge and the misconceptions of each student.

The student's level of knowledge will be represented by a knowledge tree with an assigned fuzzy variable knowledge to each element of the KE tree, representing the knowledge of a student in this KE. Similarly, the student's misconceptions are described through the misconception tree, which assigns a fuzzy variable misconception to each element of the KE tree. When a student starts to take a course, the student's progress is monitored in the system through the student's knowledge profile and the student's misconception profile.

When a student requests a new lesson within a course, the lesson provided is not necessarily the lesson defined in the sequence chosen by the content provider. In fact, each lesson is associated with a set of KE prerequisites that should be satisfied for the student to be able to understand the lesson. For each KE, the value of the student's misconceptions and the student's knowledge will be inspected. If the misconceptions of a given prerequisite's KE exceed a pre-defined threshold, an intelligent agent, named the Lesson Selection Agents (LSA), will be created. Similarly, an LSA will be created for each prerequisite's KE whose lack of knowledge value is bigger than the threshold. The lack of knowledge represents the knowledge that the student does not have and is equal to 1 minus the knowledge of the student in a KE. 
To choose the next lesson, the set of agents will go into a negotiation phase to determine whether the next lesson will be the one defined in the content provider's sequence or another lesson that covers a lack of knowledge or misconception from which the student suffers. This negotiation is conducted using fuzzy rules and will be discussed in more details in the next section.

After each lesson, the student will be subject to an exam. The exam questions may be related to the lesson that the student has just taken or to the KEs that have a misconception value or a lack of knowledge value that exceed a predefine threshold. In fact, the system will create an intelligent agent, named the Examiner Agent (EA), for the current lesson and for each misconception and lack of knowledge exceeding this threshold. The agents will go into a negotiation phase, conducted using fuzzy rules, to distribute the available questions between the agents. The details of the question distribution will be provided in the next section.

When a question is presented to a student in a test, this information is stored in the database with the correctness of the student's answer. A question's probability of being included in a test depends on parameters such as the relevance of the question, the profile of the student, the last date this question was presented to the student (if ever) and the previous correctness of the answer. In fact, a question that has been presented to a student will have a period of restriction time during which the question cannot be presented again to the same student in another quiz. After this restriction period, a question that has been previously answered in a wrong way will be more likely to be presented again to the student. A question that was entered by the content provider of the course that the student is taking will also have higher priority to be chosen over questions that have been entered by other content providers.

When lessons are presented to a student and when questions are correctly answered by a student, the value of the misconception and knowledge of the related KEs will improve through the Assessment Agent (AA). KEs that have a higher weight in a question or a lesson will improve better than KEs with lower rates, and vice versa. Similarly, false answers will increase the misconceptions and decrease the knowledge of the related KEs. The amount by which the misconceptions and knowledge are increased or decreased is not constants. Instead, they are a function of the number of misconceptions that the student has about the related KE. In fact, when a student is presented with new mathematical concepts and when the student answers related questions correctly, the system use a higher rate of increase in the knowledge of the student. When the student is presented with lessons and questions to a misconception of the student, the values related to the KE should not increase with a high rate as this correct answer may be the result of a lucky guess or the result of elimination of other possible answers to the question. A KE with a high misconception will result in a higher number of questions related to that KE to be chosen in the exam and we do not want to risk stopping the examination of a misconception prematurely. To achieve this effect, the rate of increase or decrease of a misconception and knowledge depends on the value of the misconception.

\section{Managing the e-learning system through multi-agents' interaction}

The main goal of this research is to model the knowledge and misconceptions of the student and to provide the student with the material that would help him or her overcome these misconceptions and missing information before starting a lesson. The system is implemented using a multi-agent architecture, where the material presented to the student is chosen based on the interaction between the agents.

The lesson presented to the user is chosen by the Lesson Selection Agent (LSA). Before presenting a lesson to the student from the course the student is taking, the prerequisites of this lesson are compared to the student's profile. If the student's level of knowledge or misconceptions is unsatisfactory, the LSA creates a Teaching Agent (TA) for each detected misconception or missing knowledge related to these prerequisites. The LSA will also create a Curriculum Agent (CA), which will always propose the next lesson from the current course that the student is taking. Conflict will occur between the CA and the TAs, as each agent will try to push different lessons. Each TA will use the values of the dependency of the prerequisite the agent is representing, which reflects the importance of this prerequisite towards the understanding of the lesson, and the level of misconceptions of the student or missing knowledge in this prerequisite to determine the demand of the TA. The demand is another fuzzy variable expressing how crucial the need is to present teaching material to the student to explain this prerequisite before giving him or her the lesson of the course. On the other hand, the demand of the CA is a function of the progress of the student in the unit being taught, starting from a system constant and increasing with the progress of the student in the course. It is implemented this way to express 
the need not to interrupt the current unit being taught when the student is near the end of this unit unless really needed. The LSA will compare the demands of the TAs and that of the CA and will choose to offer the lesson proposed by the agent with the highest demand.

The system uses 3 fuzzy variables: the misconceptions, the lack-of-knowledge and the dependency between the subjects. Each fuzzy variable has 3 labels: high, intermediate and small. Figure 5 shows the set of fuzzy rules that determine the demand of the TA representing the misconception of the student in a prerequisite. The system uses the center-of-gravity technique to determine the crisp value of the demand level of a TA. The fuzzy rules were implemented using jFuzzyLogic (Cingolani and Alcala-Fdez, 2012).

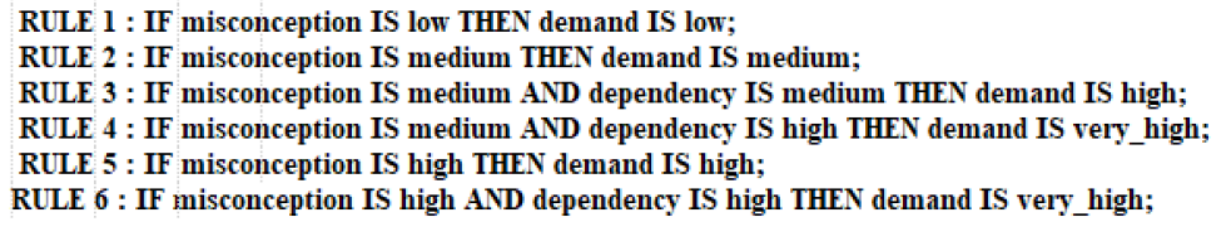

Figure 5: Fuzzy Rules Determining the Demand Level of a Training Agent

The Examiner Agent (EA) is responsible for choosing the set of questions to be presented to the student in an exam. The EA will contain multiple sub-agents that compete for the available question slots. The EA will create a Course Exam Agent (CEA) that is responsible for proposing questions related to the course's lessons that the student has recently taken. For each misconception exceeding a predefined level and for each knowledge element below a predefined level, a Quiz Agent (QA) will be created. The QA is responsible for proposing questions to further test the knowledge of the students in the KEs related to the misconceptions or missing knowledge of the student. This problem can be represented as a resource distribution problem where a fixed number of resources, which are the number of questions that will be presented in the exam, will be distributed between the agents that are proposing questions. Similarly to the LSA, QA demand will be a function of the misconception and knowledge variables and will increase if these misconceptions and missing knowledge are related to prerequisites of the current course. The EA will arbitrate between the conflicting agents using fuzzy rules to evaluate the demand level of each agent. The EA will assign a percentage of questions to each agent based on the agent's demand.

To evaluate the effect of the system, it is planned to use a test group with problems in mathematics. The group will be tested at the beginning of the course to deduce the lack of knowledge and misconceptions of each student. The group will be divided into two sub-groups. The first will only use the classroom environment to teach the new course. The second group will use the electronic system with the help of teaching assistants instead of the classroom. At the end of the course, each sub-group will be evaluated to determine the effect of using the proposed system on improving the student levels.

\section{Conclusion}

In this paper, we presented an innovative architecture for building an e-learning system using a multi-agent architecture.

The system is capable of tracking the progress of the student through the tracking of knowledge and misconceptions. Based on the progress of each student, the system provides the student with the learning material that is needed for the student to be able to progress in the course. Based on the prerequisites of each section and the weaknesses of the students, the system may provide the student with material that covers the knowledge areas in which the student lacks the required knowledge or has misconceptions in. When the system suspects that the student has a weakness in a knowledge area, the system increases the number of questions related to this area to help evaluate the level of the student and eventually provide the student with the needed teaching material.

\section{References}

ADAMS, D. M., MCLAREN, B. M., DURKIN, K., MAYER, R. E., RITTLE-JOHNSON, B., ISOTANI, S. and VAN VELSEN, M. 2014. Using erroneous examples to improve mathematics learning with a web-based tutoring system. Computers in Human Behavior, 36, pp. 401-411. 
AL DUHAYYIM, M. and NEWBURY, P. 2018. Adaptive e-learning system using fuzzy logic and concept map. World Academy of Science, Engineering and Technology, International Journal of Educational and Pedagogical Sciences, 12, pp. 11041111.

BADARACCO, M. and MARTINEZ, L. 2011. An intelligent tutoring system architecture for competency-based learning. Knowledge-Based and Intelligent Information and Engineering Systems, Pt li, 6882, pp. 124-133.

BADARACCO, M. and MARTINEZ, L. 2013. A fuzzy linguistic algorithm for adaptive test in Intelligent Tutoring System based on competences. Expert Systems with Applications, 40, pp. 3073-3086.

BARTELET, D., VAESSEN, A., BLOMERT, L. and ANSARI, D. 2014. What basic number processing measures in kindergarten explain unique variability in first-grade arithmetic proficiency? Journal of Experimental Child Psychology, 117, pp. 1228.

BERCH, D. B. 2017. Why learning common fractions is uncommonly difficult: unique challenges faced by students with mathematical disabilities. Journal of Learning Disabilities, 50, pp. 651-654.

BOYLE, E. A., HAINEY, T., CONNOLLY, T. M., GRAY, G., EARP, J., OTT, M., LIM, T., NINAUS, M., RIBEIRO, C. and PEREIRA, J. 2016. An update to the systematic literature review of empirical evidence of the impacts and outcomes of computer games and serious games. Computers \& Education, 94, pp. 178-192.

CINGOLANI, P. and ALCALA-FDEZ, J. 2012. FuzzyLogic: a robust and flexible fuzzy-logic inference system language implementation. 2012 leee International Conference on Fuzzy Systems (Fuzz-leee).

DEVLIN, K. 2001. The Math gene: how mathematical thinking evolved and why numbers are like gossip. United States: Basic Books.

ECHEVERRIA, A., AMESTICA, M., GIL, F., NUSSBAUM, M., BARRIOS, E. and LECLERC, S. 2012. Exploring different technological platforms for supporting co-located collaborative games in the classroom. Computers in Human Behavior, 28, pp. 1170-1177.

ERYILMAZ, M. and ADABASHI, A. 2020. Development of an intelligent tutoring system using Bayesian networks and fuzzy logic for a higher student academic performance. Applied Sciences, 10(19).

FISCHER, F., KOLLAR, I., STEGMANN, K. and WECKER, C. 2013. Toward a script theory of guidance in computer-supported collaborative learning. Educational Psychologist, 48, pp. 56-66.

FRANKLIN, S. and GRAESSER, A. 1997. Is It an agent, or just a program?: A taxonomy for autonomous agents. In: J. P. MÜLLER, M. J. WOOLDRIDGE and N. R. JENNINGS, (eds.) Intelligent Agents III Agent Theories, Architectures, and Languages (ATAL 1996). Berlin, Heidelberg: Springer.

GEARY, D. C., HOARD, M. K., NUGENT, L. and BAILEY, D. H. 2012. Mathematical cognition deficits in children with learning disabilities and persistent low achievement: a five-year prospective study. Journal of Educational Psychology, 104, pp. 206-223.

GOGUADZE, G., SOSNOVSKY, S., ISOTANI., S., MCLAREN, B.M. Evaluating a Bayesian student model of decimal misconceptions. 4th International Conference on Educational Data Mining, 2011 Eindhoven, The Netherlands.

GOODYEAR P. and JONES C., T. K. 2014. Computer-supported collaborative learning: instructional approaches, group processes and educational designs. In: J. Spector, M. Merrill, J. Elen, M. Bishop (eds) Handbook of Research on Educational Communications and Technology. Springer, New York, NY., https://doi.org/10.1007/978-1-4614-3185$\underline{535}$.

KAROLL, D. 2008. Why is Math so hard for some children? The nature and origins of Mathematical learning difficulties and disabilities. Journal of Developmental \& Behavioral Pediatrics, 29.

KUCIAN, K., ASHKENAZI, S. S., HANGGI, J., ROTZER, S., JANCKE, L., MARTIN, E. and VON ASTER, M. 2014. Developmental dyscalculia: a dysconnection syndrome? Brain Structure and Function, 219, pp. 1721-33.

KUCIAN, K., GROND, U., ROTZER, S., HENZI, B., SCHONMANN, C., PLANGGER, F., GALLI, M., MARTIN, E. and VON ASTER, M. 2011. Mental number line training in children with developmental dyscalculia. Neuroimage, 57, pp. 782-795.

LAI, K. R., CHOU, C. Y. and LAN, C. H. 2012. Supporting adaptive learning sequences with agent negotiation. 2012 IEEE 12 th International Conference on Advanced Learning Technologies. IEEE.

LAI, K. R., CHUNG HSIEN, L. and CHEN CHUNG, L. 2006. Application of agent negotiation in supporting adaptive learning. Sixth IEEE International Conference on Advanced Learning Technologies (ICALT'O6),. Kerkrade: IEEE.

LAI, K. R. and LAN, C.-H. 2012. Learning through agent negotiation: a conceptual framework. In: IEEE (ed.) 2012 IEEE Fourth International Conference On Digital Game And Intelligent Toy Enhanced Learning.

LI, Q. and MA, X. 2010. A meta-analysis of the effects of computer technology on school students' Mathematics learning. Educational Psychology Review, 22, pp. 215-243.

MCLAREN, B. M., ADAMS, D., DURKIN, K., GOGUADZE, G., MAYER, R. E., RITTLE-JOHNSON, B., SOSNOVSKY, S., ISOTANI, S. and VAN VELSEN, M. 2012. To err Is human, to explain and correct Is divine: a study of interactive erroneous examples with middle school Math students. 21st Century Learning for 21st Century Skills, 7563, pp. 222-235.

MOELLER, K., FISCHER, U., NUERK, H. C. and CRESS, U. 2015. Computers in mathematics education - Training the mental number line. Computers in Human Behavior, 48, pp. 597-607.

NYE, B. D. 2015. Intelligent tutoring systems by and for the developing world: a review of trends and approaches for educational technology in a global context. International Journal of Artificial Intelligence in Education, 25, pp. 177203.

HOBUN, P. and VICHEANPANYA, J. 2010. Adaptive intelligent tutoring systems for e-learning systems. Innovation and Creativity in Education, 2, pp. 4064-4069. 
RUSSELL, M., O'DWYER, L. M. and MIRANDA, H. 2009. Diagnosing students' misconceptions in algebra: Results from an experimental pilot study. Behavior Research Methods, 41, pp. 414-424.

SHUTE, V. J., ZAPATA-RIVERA, D., DURLACH, P. J. and LESGOLD, A. M. 2012. Adaptive Educational Systems. In: P. J. DURLACH, A. M. Lesgold (eds.) Adaptive Technologies for Training and Education. Cambridge: Cambridge University Press.

SOLIMENO, A., MEBANE, M. E., TOMAI, M. and FRANCESCATO, D. 2008. The influence of students and teachers characteristics on the efficacy of face-to-face and computer supported collaborative learning. Computers \& Education, 51, pp. 109-128.

SULLIVAN, P., BORCEK, C., WALKER, N. and RENNIE, M. 2016. Exploring a structure for mathematics lessons that initiate learning by activating cognition on challenging tasks. Journal of Mathematical Behavior, 41, pp. 159-170.

WOOLDRIDGE, M. 2002. Intelligent Agents: The Key Concepts. Berlin, New York: Springer.

ZHANG, X., DE PABLOS, P. O. and ZHU, H. L. 2012. The Impact of Second Life on Team Learning Outcomes from the Perspective of IT Capabilities. International Journal of Engineering Education, 28, pp. 1388-1392.

ZHANG, X., MA, H., WU, Y. N., DE PABLOS, P. O. and WANG, W. G. 2014. Applying Cloud Computing Technologies to Upgrade the Resource Configuration of Laboratory Course: The Case of Quality Engineering Education Platform. International Journal of Engineering Education, 30, pp. 596-602. 